\section{BESPOKE IMPLANTOLOGY STORAGE SOLUTIONS}

Highline bespoke healthcare storage solutions from Support Chairs are the ultimate answer in mobile storage systems. Their Implantology Trolleys incorporate a variety of features designed to make implantology even easier and more efficient. Available

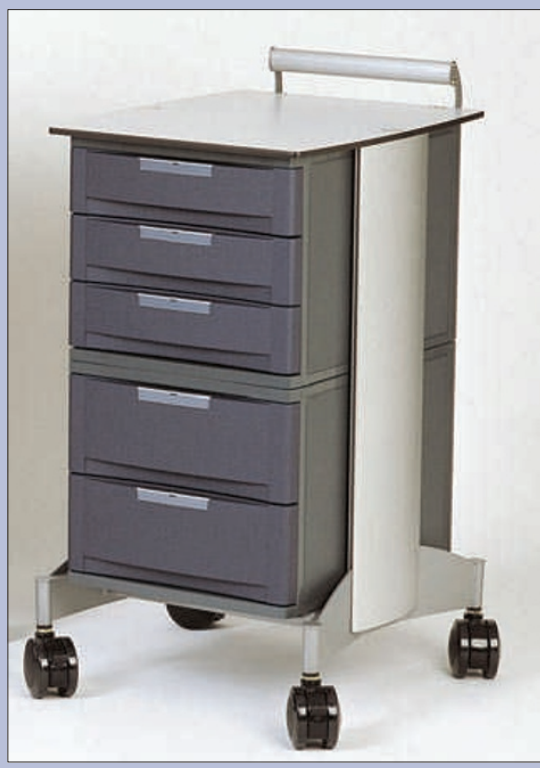

in a choice of nine formats they are extremely versatile and cost-effective.

Composed of modules containing sets of four different drawer sizes, they can be combined in one of nine models to create units of the required height, width and mixture of drawer sizes. Some models feature an open space for storing equipment, or a glass fronted lockable cupboard with a height adjustable shelf. All are fitted with high quality wheels, offering high ground clearance for easy movement and hygiene, and handles as standard. Two of the wheels are lockable.

Stylish and efficient, Highline Implantology Trolleys are constructed from aluminium, steel and high quality plastics which are resistant to most stains including blood. Drawer fronts are available in either simulated aluminium or navy metallic finish. Additional extra options include drawer locks and various instrument trays and drawer dividers. Reader response number 54

\title{
SUPPORT FOR DEALING WITH DENTAL PHOBIA
}

Specialist website www.dentalphobia. co.uk offers both patients and practitioners extensive support, advice and up-to-date information on accepting and dealing with dental treatment.

The site is the highest ranking website on search engine Google for the key phrase 'dental phobia', and provides visitors with useful features such as patient case studies, information on the latest treatments available, and detailed explanations of the most common dental procedures. Not only is the site an ideal point of reference to which to direct nervous patients, but it is also a useful research tool for practitioners who wish to learn more about how best to treat phobic patients.

The site also features an extensive directory of 'Dental Phobia Certified' practitioners. With information on hundreds of practices located across the country, the database is invaluable when searching for a practitioner who understands the fears and requirements of a phobic patient.

Reader response number 55

\section{IMPROVE PROFITABILITY}

CEREC $^{\circledR}$ from Ceramic Systems enables dentists to create high quality and durable chairside all-ceramic restorations, including restorations for implant retained crowns and bridges, in the most cost effective and efficient way.

CEREC $^{\circledR}$ is a computer-aided method for creating precision fitting all-ceramic restorations. It enables dentists to design and create all-ceramic inlays, onlays, partial crowns, veneers and crowns for the anterior, premolar and molar regions in one visit. Eliminating the need for impressions, CEREC $^{\circledR}$ utilises a digital impression taking technique to capture the data used to design the restoration which is then milled in the milling unit. The milling unit can be situated anywhere that is convenient within the practice, even as a fascinating eyecatcher in the waiting room.

Combined with adhesive bonding techniques, CEREC ${ }^{\circledR}$ creates biocompatible, non-metallic, natural-looking restorations from durable high-quality ceramic materials in a single treatment session - without the need for provisional restorations.

CEREC ${ }^{\circledR}$ specialists Ceramic Systems provide dedicated service and support engineers, countrywide product specialists for pre- and after-sales support, lowcost finance arrangements, user meetings, a Gold Club for software upgrades, service and support, a dedicated training facility and courses by Ceramic Systems' exclusive Trainer Dr Simon Smyth.

\section{Reader response number 57}

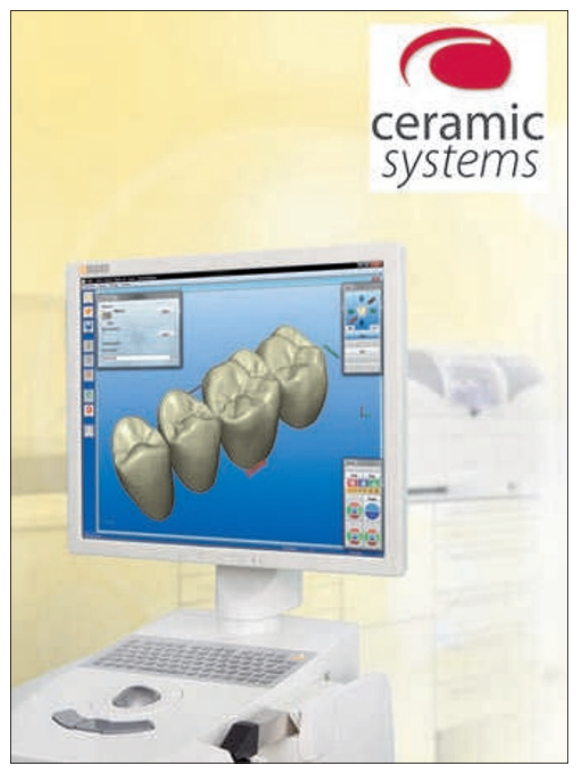

